\title{
Correspondence
}

\section{Special Committee on Political Abuse of Psychiatry}

DeAR SiR,

Dr Levine's report of the Special Committee on the Political Abuse of Psychiatry (Bulletin, May 1981, p. 94) was welcome, and it is good to know that the College has been so active in the defence of individuals who are the victims of such abuse, and that it has addressed our colleagues in the USSR so directly on these matters. I hope, however, that the College will not fall into the trap of seeming to suggest that the 'first-rank' symptoms of oppression are confined to one country, however fashionable such a view may be. That this is a risk is suggested by the strange comment that the differentiation in standards of psychiatric care according to skin colour in South Africa is 'not considered to be primarily political'. What is considered political is ultimately a political decision; for example, to come nearer home, if psychiatrists were called upon to advise on civil defence or on life in the post-nuclear warfare age, would those responding be acting responsibly and professionally, or would this represent (as I believe) a political abuse, serving to prepare the minds of people to accept the idea that the unthinkable horror of nuclear warfare is not unthinkable?

While I hope the College will sustain its role in relation to psychiatry in the USSR, I believe that the Committee, even if necessarily 'empowered to act independently', should consult very fully with the members on these matters, and should show a proper breadth and impartiality in its concern with abuse, as does, for example, Amnesty International. Until then we should not settle down too snugly and smugly under Edmund Burke's mantle.

University of Sussex

ANTHONY RYLE

Brighton

\section{Obstacles and rivals}

DEAR SIR

I was interested to read Norman Imlah's letter 'An obstacle to in-patient treatment' (April, 1981, p. 72), with his experience of problems in working with the Social Services Department, particularly in the matter of compulsory admission of patients to hospital under the Mental Health Act. We too, in the York area, have had problems precisely of the kind that Dr Imlah describes, particularly from the younger social worker, whose theoretical training seems to be somewhat out of touch with the realities of the duties of a mental welfare officer! However, it is hoped that this is a teething problem resulting from the reorganization to the generic social worker which occurred a few years ago, and that as those social workers gain experience, they will become more pragmatic.

This problem, however, seems to me to be symptomatic of a more general difficulty in the relationships between established professions, particularly, in this context, medicine and psychiatry, and the professions which are establishing themselves in related fields.

We have found particular difficulty in the last year or two in our relationship with our clinical psychology colleagues, and this would seem to be primarily the fault of the Trethowan report, or perhaps its over-enthusiastic application.

Clinical psychology, having at one time been a profession that worked within the psychiatric hospital and under the umbrella of consultant psychiatry cover, has now become a district-based service doing its own thing, which in practical terms seems to mean that it has set up as a rival therapeutic group practising its own brand of therapy, and in competition with the established NHS psychiatric service.

Indeed, a rival therapeutic team is now in our area giving sessional time at health centres and direct referrals are being made for treatment by general practitioners to these nonmedically qualified therapists, presumably with the general practitioner continuing to take the legal responsibility for the patient. In practice this is leading to a demarcation dispute where it would seem that the clinical psychologists now consider that they are the experts in the treatment of neuroses, and that psychiatrists should confine themselves to psychotic illness and the dementias!

I cannot think that these trends are healthy to psychiatry as a profession, since our own caseloads are absurdly large in contrast to those currently accepted by the other professions (clinical psychology and social work), resulting in fact in our probably giving a poorer service, but being unable to expand our own professional team because of financial constraints.

It would seem to me that the implications of the Trethowan report were not really thought through at the time, and that the way in which the situation is developing is something which should be causing psychiatrists a considerable disquiet. I wonder if other readers have similar experiences.

\section{Clifton Hospital}

M. T. HAsLAM

York YO3 6RD

\section{DeAR SIR}

\section{Police use of hypnosits}

I have been asked to prepare a list of professional people interested in attending a seminar at the Home Office early in September on the vexed question of the use of hypnosis in 
the gathering of evidence by the police. The seminar will be addressed by Professor Martin Orne of the University of Pennsylvania, who has made an extensive study of this matter, and who has advised the Supreme Courts of more than one American state.

The practice of hypnotizing witnesses, victims and even defendants is now widespread in the USA, and it is spreading to other countries, including Britain. It has raised a host of legal and ethical problems. In some states of the USA police officers are being trained to use hypnosis, and this has led to a resolution by the International Society of Hypnosis that the official use of hypnosis should be restricted to professionally trained people within the academic and clinical disciplines represented in that body. In some places the police use the services of self-styled 'experts', sometimes people who have rather minimal qualifications and who have somewhat naive concepts of how memory can be enhanced by hypnosis. The problems of confabulation, fantasy and suggestion contaminating the evidence which may later be given in court are obvious, and some eminent authorities in forensic psychology and psychiatry would ban the practice of hypnosis in this context altogether. Not least among the problems is the ambiguity as to whether hypnosis has any power at all to revivify accurate memory, other than by removing pathological amnesic blocks where they exist.

The British Home Office is taking the sensible view that it should bring together experts in a number of related fields to initiate an informed debate, before issuing any definite guidance to the various police forces of this country, and they have sought my assistance to this end. Attendance at the seminar in September will be by personal invitation, and I should therefore be glad to hear from people who are interested and feel that their qualifications are relevant.

H. B. Grison

Chairman

British Society of Experimental and Clinical Hypnosis

10 Manhattan Drive

Cambridge CB4 IJL

\section{Audio-Visual Sub-Committee}

Dear SIR,

The Audio-Visual Sub-Committee is concerned about the relative lack of tape-slide teaching programmes on all aspects of psychiatry compared to other specialties and would like to draw attention to the facilities offered by the Graves Medical Audio-Visual Library for the making and distribution of such programmes.

Dr Valerie Graves, the Honorary Medical Director, will assist in the making of slides and the tape recording if necessary, any expenses are met, and there is a fee of $£ 50$ representing advance royalties. Further royalties may be earned later and the producer is given a copy for his own use.

If any members of the College are prepared to offer programmes of not more than thirty minutes on any subject of value to trainees, I would be grateful if they would get in touch with myself in the first instance.

Tom Pilkington

Claypenny Hospital

York Y06 3PR

\section{Reviews}

Critical Psychiatry: The Politics of Mental Health. Edited by David Ingleby. 1981. Penguin Books. £2.95.

They asked me for a sympathetic review-'we ought to know what these anti-psychiatrists are up to, perhaps we have something to learn'-and indeed I approached the book with hope. I am all for critical examination of our assumptions, practices and relations with others, and trying to do better in future: and a political approach could be refreshing. Ingleby has been based in the Cambridge Psychological Laboratory for nine years or so, and he has contributed just under a third of this 200-page book. The other seven contributors include another psychologist, three sociologists, and three psychiatrists. One of the psychiatrists (F. Basaglia) is already well known-see Roth's paper on 'Psychiatry and its Critics' in British Journal of Psychiatry.
122, 373 (1973). His account here of closing down a mental hospital in Trieste and moving mental health services into the community is unfortunately too sketchy and lacking in factual information for us to see how it differs from the many other attempts at the same thing in other countries, for example the work of Scott at Napsbury, and one gets nothing from it. Hangsgjerd from Norway is an analyst who is also a Marxist, and he devotes part of his chapter to 'the most important recent political event in the mental health field ... the struggle against the Common Market.' There is a chapter also on French anti-psychiatry (by an American sociologist), from which it appears that some psychoanalytical groups are more Marxist than others. Indeed, let us be frank and get it out of the way: the 'Politics' of the title is narrower than I hoped, and really means Marxism. I didn't find these foreign contributions in any way enlightening, partly for a reason I shall come to later, and it seemed to me 